conscious life are hunger and thirst; lack of sleep due to intense cold ; monotony of colour, work, companionship ; gruelling work ; inseparability from companions; and physical dangers. Hunger produces a craving almost unbearable. The party talks food, thinks food, and dreams food. Lack of sleep is lowering physically, and the temperament suffers. Unvaried monotony induces a monotone of mood, taciturnity, intolerance of waggishness, and ready irritation. Conversation becomes taboo, raillery unsafe. With prolongation of stress illusions become frequent and affect the whole party uniformly. The gruelling work leads to the obsession that companions are all "slacking in the trace." This occurs in the noblest characters, and among friends of tested worth. Companionship is perpetual-the opposite of loneliness ; in fact, homesickness is absent almost always. Temporary loneliness at any cost is desired, and it is impossible, for all tasks must be done in pairs.

The predominant effects on mind and temperament seemed to be most revealed in dreams. Most prominent were dreams of food, relief, and disaster to companies. Food dreams were undoubtedly first, and among them some in great detail in which it was suddenly realised that a shop or restaurant lay just round the hill, where all these creature needs could be supplied-arrival there proved it closing day, and too late. To smokers the shop would be a tobacconist's ; in all cases, however, the shop was closed. Relating of one's dreams to one's fellows became a relaxation. Two of the party were of lethargic temperament; these dreamed of feasts and always achieved satisfaction. The other four always awoke from the dream when the food was laid and did not taste of it. The two could describe with gusto the menus they went through. This became a grievance to the rest, who had to reason themselves out of the idea that an unfair advantage had been taken, as the feeling developed that to equalise matters the rations of the two should be reduced.

Men mentally unfitted for polar work are liable to temporary mental aberration during or immediately after an expedition, but most readily in real hardship. The patient is irresponsible, and has the most extraordinary hallucinations. One most important conclusion appears to emerge, viz., that the inelastic mind and temperament succumbs, whereas the more highly-strung and sensitive type better understands unprecedented strain.

JOHN GIFFORD.

\title{
2. Neurology.
}

A Review of Recent Literature on Neurosyphilis. (Archiv Neur. and Psychiat., February, 1922.) Solomon, H.C.

The author singles out the new edition of Nonne's Syphilis und Nervensystem, and a new book by Wilhelm Gennerich, Die Syphilis des Zentralnervensystems, which he regards as the most important work on neuro-syphilis published to date.

Are there strains of spirochætes with predilection for the nervous system? Marie and Levaditi, in 1920, reviewed the various theories in favour thereof. They note the infrequency with which active 
skin lesions have occurred in neuro-syphilitic cases; also patients infected from the latter source develop neuro-syphilis. In experimental work in I9I3 they inoculated a rabbit with human blood from a case of general paresis; the disease took and was passed through three generations of the animal. The incubation period was two to three times as long as that when infection was by spirochæte from primary lesions.

Rabbits inoculated with paretic virus are not immune to the virus from other sources. In the dermatropic strain average incubation is 42 days, in the neurotropic 95 days. By a second inoculation these periods are reduced respectively to 15 days and 75 days. The primary lesion in the dermatropic strain is indurated with marked border ulceration, and results in endarteritis, periarteritis with intense infiltration, and much subsequent new connective tissue; in the neurotropic type there is papulo-squamous erosion with slight ulceration and desquamation, the sequelæ being perivascular lesions with little endarteritis and less new tissue formation.

The monkey took the dermatropic, but not the neurotropic strain. Man receives the dermatropic type, but the experiments were not here successful in reproducing the neural disease. The elucidations have been severely criticised, and are not final, but none the less are among the most important contributions to the subject.

Wile and Hasley observe that the spinal Wassermann reaction is positive prior to that in the blood.

McIver, in the primary and secondary stages of syphilis, found slight lymphocytosis in the majority of cases, protein increase occurs later, and positive Wassermann was absent, using 6 c.c. fluid; he concludes it is not reasonable to assume that the spinal Wassermann will indicate which patients will develop central nervous system syphilis.

Nicolau, in 51 primary cases, found lymphocytosis in eighteen at the beginning of the third week; with adenopathy this is one of the earliest manifestations of general infection. Pupillary inequality was found to be highly suggestive of cerebro-spinal lymphocytosis.

In a series of 624 early cases of syphilis affected more than six months and without symptoms, 35 per cent. had abnormal central nervous systems. Lack of symptoms is the outstanding feature; few patients complain of disability in syphilitic meningitis even when the cerebro-spinal fluid is visibly opalescent. Hence in all early syphilis the nervous central system should be thoroughly investigated, which is rarely done by the syphilologist.

The "abortive treatment " in the incipient primary period leads to the discharge of patients as cured, yet in such neurosyphilis develops later. Many writers concur in the advocation of intraspinal treatment to produce a negative spinal Wassermann. Solomon agrees that six to eight injections of arsphenamin followed by mercury leave a positive fluid, but intensive administration (larger and more frequent doses over a longer time) will produce normality in the spinal fluidtreatment sufficient to suppress secondary skin lesions is quite inadequate.

Nicolau further cautions that a persistently negative Wassermann

IXVIII. 
consequent on treatment is not dependable as a proof of the abortion or cure of the disease ; there must also be evidence of non-irritation of the cerebrospinal fluid. Solomon believes this one of the most valuable dicta recently enunciated.

It is then definitely shown that in syphilis the cerebrospinal axis is early infected in many cases. Suitable combative measures should therefore be immediately adopted.

JOHN GIFFORD.

\section{Clinical Psychiatry.}

Thyroidal Psychoses [Les psychoses thyroïdiennes]. (Le Prog. Méd., April, 1922.) Laignel-Lavastine.

The present article is chiefly concerned with those thyroid abnormalities which have been found associated with the so-called affective psychoses. The author himself has met with many cases of melancholia, hypomania, and anxiety psychosis, which, at the same time, were goitrous. Thus in a case of agitated melancholia presenting thyroid enlargement with signs of hyperthyroidism, complete mental recovery followed the removal of a thyroid cyst. In another case of melancholia with a large goitre the latter was treated by radio-therapy, with the result that the signs of hyperthyroidism diminished and the melancholia disappeared.

In regard to the pathology of such cases the author affirms that, in spite of the diversity of lesion as shown by the microscope, they nevertheless possess one common link, viz., the more or less constant presence of the cylindrical epithelial cell, which would appear to be the histological expression of hyperthyroidism.

The question of $æ$ tiology is necessarily somewhat involved, having regard to the coincidence of thyroid disturbance and mental disorder in the same subject. It is a recognised fact that emotional shock and psychogenic factors account for the onset of many of these cases. In so far as the actual ætiological mechanism is concerned, LaignelLavastine supports the view originally put forward by Widal. The latter has shown that the mechanism is not, as was formerly believed, a chemical one; but that very often it is a physical mechanismcolloidal modifications taking place in the humours as a result of shock or other psychical cause. Thus we see that the emotions may determine not only nervous but also humoral modifications, which manifest themselves by changes in the colloidal equilibrium.

The author's clinical observations, added to the important findings of other writers, furnish convincing evidence in favour of the existence of a relationship between thyroid disturbances and mental disorders. It may be objected that, though thyroid modifications are frequent, there may be no accompanying mental perturbation. In answer to this the author points out that in order to have psychic manifestations a mental predisposition is necessary. It is therefore possible to understand that those persons who have not shown these psychological reactions possess greater cerebral resistance. Once this resistance is lowered these manifestations make their appearance.

Norman R. Phillips. 